\title{
PRESENÇA DO PENSAMENTO COMPLEXO EM PROJETO DE EAD INTERORGANIZACIONAL: O CASO PAI/UFSC
}

\author{
Aline Pereira Soares (EGC/UFSC - alinepsoares@yahoo.com.br) \\ Marina Keiko Nakayama (EGC/UFSC - marina@egc.ufsc.br) \\ Luis Roque Klering (EGC/UFSC e EA/UFRGS - lrklering@ea.ufrgs.br) \\ Ricardo Silveira Azambuja (INE/UFSC - silveira@inf.ufsc.br)
}

Resumo: O artigo apresenta um estudo de caso enfocando a análise da gestão do Projeto Aluno Integrado (PAI), promovido pelo Ministério da Educação e Cultura (MEC), no período de 2010 e 2011, na modalidade de EaD, com o objetivo de fomentar o uso pedagógico das Tecnologias de Informação e Comunicação (TICs) nas redes públicas de educação básica do Brasil. Um dos objetivos do estudo foi analisar que paradigmas teóricos nortearam a gestão do conhecimento em situação de conflito organizacional no curso PAI, nos estados do Paraná, Santa Catarina, Rio Grande do Sul e Mato Grosso do Sul, que estiveram sob a coordenação da Universidade Federal de Santa Catarina. Para compreender e analisar o caso, recorreu-se principalmente ao paradigma da complexidade, proposto por Stacey (2006) e Axelrod e Cohen (2000). A metodologia utilizada foi o estudo de caso do tipo exploratório e descritivo; levantamento de dados via documentos e entrevistas; e análise de dados com base na metodologia da Ground Theory (GT). Os resultados das análises apontaram que o paradigma interpretativista é que predomina no curso, tendo-se constatado poucos sinais de presença do pensamento complexo.

Palavras-Chave: Educação a Distância. Sistemas Adaptativos Complexos. Grouded-Theory. GT.

\section{THE PRESENCE OF COMPLEX THOUGHTS IN INTERORGANIZATIONAL DISTANCE EDUCATION PROJECTS: THE PAI/UFSC CASE}

Abstract: This article presents a case study on the analysis of the management of Projeto Aluno Integrado (Integrated Student Project) - PAI, sponsored by the Ministry of Education and Culture - MEC from 2010 to 2011, as a distance education project,; it is intended to foster the educational use of Information and Communication Technologies (ICTs) in public primary schools in Brazil. One of the goals of the study was to prove that theoretical paradigms govern knowledge management in a conflicting situation in PAI, in the States of Paraná, Santa Catarina, Rio Grande do Sul and Mato Grosso do Sul, which where under the supervision of the Federal University of Santa Catarina. In order to understand and analyze the case better, we turned to the complexity paradigm, proposed by Stacey (2006) and Axelrod and Cohen (2000). The following are the methods used: exploratory and descriptive case study; data survey through documents and interviews; data analysis based on the Ground Theory (GT) method. The results of the analyses show that the interpretative paradigm predominates in the project, with little indication of the complex paradigm.

Key-words: Distance education. Motivators conflict. Conflict interorganizational. GT.

\section{INTRODUÇÃO}

Drenth (1998) destaca que boa parte do conhecimento relacionado ao conflito no ambiente organizacional ainda está balizado por descobertas baseadas em pesquisas antigas, e que o estudo continuado torna-se fundamental. Tal fato é estimulado principalmente pelo acelerado desenvolvimento tecnológico, social e organizacional (intensificado) dos últimos anos, que ocasionou novos problemas para as organizações. O autor menciona que muitas pesquisas receberam respostas inacabadas e tantas outras não foram densamente estudadas, como é o caso do conflito interorganizacional, presente no caso ora enfocado. 
Tal fato ocorre frequentemente no cenário da Educação a Distancia, porque esta modalidade de ensino permite que diferentes agentes, dispersos geograficamente, trabalhem em conjunto. Nessa relação, o conflito é inevitável, uma vez que as equipes de EaD trabalham a quilômetros da sede, sem se conhecerem de fato. Contudo, se os agentes organizacionais aprenderem a administrar o conflito e utilizá-lo como matriz para solução de problemas (STACEY, 1996) e melhor gestão do conhecimento, os gestores poderão aprender muito sobre o próprio sistema no qual estão inseridos (MALLORY, 1997); além de combinar o conhecimento explícito ao tácito (NONAKA; TAKEUCHI, 1995). Dessa maneira, para explicar melhor as mudanças ocorridas no ambiente de trabalho deste estudo, necessita-se acrescentar aspectos baseados na complexidade.

Stacey (1996), ao explicar a complexidade dos sistemas, enfatiza que, na atual situação em que as organizações estão inseridas, a sobrevivência delas não depende exclusivamente de simples mudanças frente às pressões do ambiente, mas da capacidade que elas têm de antecipar/prever os acontecimentos, das respostas às ameaças que o conflito pode proporcionar e das oportunidades que o ambiente pode trazer, a fim de que cresçam e sobrevivam em meio a mudanças.

Dentro dessa premissa, percebeu-se a necessidade de avaliar como as estratégias foram desenvolvidas na primeira edição do Projeto Aluno Integrado, desenvolvido no período de 2010-2011, na parte coordenada pela UFSC, sob a ótica da complexidade, visando a minimizar os conflitos e possibilitar melhor compartilhamento do conhecimento. De forma a possibilitar que em futuras edições do projeto seja formada uma rede de conhecimento, desenvolvendo uma sinergia entre: instituições, gestão, estratégias, aprendizagem, pessoas e conhecimento. E baseados no pressuposto da significativa relação entre essas variáveis, e utilizando-se como base de análise as opiniões dos integrantes das equipes dos estados do Mato Grosso do Sul, Paraná, Santa Catarina e Rio Grande do Sul, elaborou-se a questão da pesquisa: Que paradigmas teóricos nortearam a gestão do conhecimento em situação de conflito interorganizacional no curso PAI - primeira edição, na parte coordenada pela UFSC?

Deste modo, neste artigo, o objetivo geral de estudo delimita-se e consiste em identificar que características dos Sistemas Adaptativos Complexos - segundo Axelrod e Cohen (2000) e Stacey (1996), foram evidenciadas no Projeto Aluno Integrado, na parte coordenada pela UFSC em 2010-2011, visando a minimizar os conflitos.

\section{TEORIAS DO PENSAMENTO COMPLEXO}

A abordagem Complexa originou-se com base em três teorias: teoria do caos, teoria dos Sistemas Adaptativos Complexos e teoria das estruturas dissipativas (CASTRO et al, 1994). Em comum, elas consideram que os sistemas se comportam de modo imprevisível e criativo, ou seja, longe do equilíbrio (que são mais exceção do que regra) previsto na Teoria dos Sistemas. Esta foi a maior falha da Teoria de Sistemas, ao considerar que a realidade de um sistema sempre está ou tende ao equilíbrio; que, após ter sido afetada por algum desvio (noise), utiliza-se de reguladores, buscando retornar ao equilíbrio (ETKIN; SCHVARSTEIN, 2000).

Segundo Allen (2001), a grande diferença entre as três teorias da complexidade "está em algumas suposições adotadas em seus modelos. A teoria dos Sistemas Adaptativos Complexos é a que mais se aproxima da realidade, seguida pela teoria das estruturas dissipativas e da teoria do caos” (PRIM, 2008, p. 36). Ou seja, ela trabalha com sistemas que se distanciam da estabilidade que, com maior complexidade, podem apresentar mais autonomia para lidar com a ordem (determinadas pelo ambiente) ou desordem (aleatoriedade) externa. Segundo Morin (1996), a criatividade, liberdade, inventividade, deixam de ser excluídas do campo da ciência, uma vez que são produto de uma auto-organização que fornece autonomia e liberdade ao mesmo tempo. Vale lembrar que até aquele momento a 
ciência tinha como maior pressuposto a confiabilidade absoluta na lógica, e qualquer contradição deveria ser descartada.

Para Morin (1996, p. 164), sistema é “[...] um conceito complexo de base porque ele não é redutível a unidades elementares, a conceitos simples, a leis gerais. O sistema é a unidade complexa”. Portanto, “[...] a concepção de sistema é a raiz da complexidade” (MORIN, 2005, p. 187).

O pensamento complexo não recusa de modo algum a clareza, a ordem, o determinismo. Ele os considera insuficientes, sabe que não se pode programar a descoberta, o conhecimento, nem a ação. O que o pensamento complexo pode fazer é dar, a cada um, um memento, um lembrete, avisando: não esqueça que a realidade é mutante, não esqueça que o novo pode surgir e, de todo modo, vai surgir.

Os Sistemas Adaptativos Complexos são complexos porque estão muito além da capacidade descritiva da ciência, e são adaptativos por sua capacidade de se adaptar a novas condições que lhes são impostas pelo seu ambiente - interno e externo.

\section{SISTEMAS ADAPTATIVOS COMPLEXOS}

A área da complexidade que estuda a adaptação é chamada de Sistemas Adaptativos Complexos. São sistemas compostos por uma multiplicidade de agentes que, para atingirem suas metas, interagem entre si, aprendem comportamentos diferentes dos iniciais e evoluem. Neste sentido, são constituídos por muitos agentes que, para interagirem entre si, elaboram estratégias que os tornam adaptados a sobreviverem e, portanto, garantirem a sobrevivência do sistema do qual fazem parte (STACEY, 1996; HOLLAND, 1995).

A representação matemática dos Sistemas Adaptativos Complexos é similar à dos sistemas dinâmicos e de auto-organização. A diferença está no fato de que nos Sistemas Adaptativos a estratégia de modelagem matemática é do tipo bottom-up, ou seja, seus comportamentos podem ser descritos por regras de interação, e a partir das interações locais os agentes se adaptam e modificam as regras fundamentadas nas experiências acumuladas e, destas interações entre os agentes, emerge o comportamento global do sistema (STACEY, 2001; HOLLAND, 1995; 1998). Esta característica peculiar, da capacidade de aprenderem, permite que os Sistemas Adaptativos Complexos se comportem de um modo diferente dos modelos das estruturas dissipativas e da teoria do caos. Ressalta-se que nem todos os tipos de Sistemas Adaptativos Complexos apresentam um funcionamento diferenciado; entretanto, o resultado mais importante em tais sistemas está na capacidade de aprender durante seu funcionamento.

Para Morin (2001, p. 150), quando se analisa uma organização sob a ótica da complexidade, tem-se que "um sistema não é somente constituído de partes, ele tem qualidades, propriedades ditas emergentes, que não existem nas partes isoladas: em outras palavras, o todo é mais do que a soma das partes”. Sendo assim, uma situação de conflito, como resultante de um processo de interação, pode revelar, dentro do pensamento sistêmico, uma forte tendência de auto-organização do sistema.

Com base em Stacey, Griffin e Shaw (2000), Axelrod e Cohen (2000), Bauer (2008) dentre outros, as organizações podem ser entendidas a partir de uma composição de agentes que elaboram estratégias e examinam os resultados de suas ações. Deste modo, faz-se importante mencionar alguns conceitos de Sistemas Adaptativos Complexos trazidos por estes autores, a saber: a complexidade é formada por estratégia, ou seja, a maneira pela qual um agente (que pode ser uma pessoa, uma família ou uma equipe, que tem a habilidade de interagir com o seu meio, incluindo ou não outros agentes), reage ao seu meio e persegue seus objetivos.

Geralmente, agentes humanos têm ideias de suas próprias estratégias, e eles podem ser capazes de prever se estão caminhando de acordo com alguma das medidas de sucesso. As 
populações de agentes são importantes para quem quer dominar a complexidade porque servem como fonte de possibilidades onde aprender, como recipientes para um aperfeiçoamento recém-descoberto, e como parte do seu ambiente.

O termo sistema é usado por Axelrod e Cohen (2000) para englobar todos estes conceitos de populações de agentes, estratégias de agentes, juntamente com os artefatos relevantes e fatores ambientais. Segundo os autores, o que torna um sistema complexo são as fortes interações entre seus elementos, de tal forma que os eventos atuais influenciam pesadamente as probabilidades de muitos tipos de eventos posteriores. Assim, os sistemas complexos podem mudar e tal fato acontece por influencia dos agentes e de suas estratégias.

Como existem vários processos de mudança de estratégia, é mais fácil interpretá-los como diferentes modos de seleção. Quando um processo de seleção de fato leva ao aperfeiçoamento, conforme alguma medida de sucesso, os autores denominam tal como adaptação (AXELROD; COHEN, 2000). Contudo, quando um sistema contém agentes ou populações que procuram se adaptar, usa-se o termo Sistema Adaptativo Complexo. E, quando múltiplas populações de agentes estão se adaptando umas às outras, o resultado é um processo coevolucionário. Esta adaptação acontece porque os agentes mudam as regras por meio de experiências acumuladas (HOLLAND, 1995).

A utilização do termo "Sistema Adaptativo Complexo" (AXELROD; COHEN, 2000), pode ser usada em duas situações: a) quando os agentes podem se adaptar e b) quando o termo diz apenas que as partes estão se adaptando, não sendo necessariamente o todo. Ao agirem/atuarem, os sistemas estão em constante aprendizado e posteriormente se adaptam; esta aprendizagem pode acontecer por loop simples, em que há absorção de esquemas préexistentes, pois os novos fracassaram e são abandonados; ou o loop duplo, quando há combinação de esquemas existentes que irão constituir e será base para novos esquemas (STACEY, 2001; KELLY; ALLISON, 1999).

\section{EDUCAÇÃO A DISTÂNCIA}

Segundo Moore, Kearsley (2012, p. 2), a principal característica da EaD é o aprendizado planejado que normalmente acontece em diferentes locais através do ensino. "Os resultados provêm de técnicas especiais no design do curso, técnicas instrucionais especiais, métodos especiais de comunicação através da eletrônica, bem como uma organização especial e arranjos administrativos”. Klering (2006) complementa esta perspectiva, apresentando algumas vantagens da EaD, tais como: o grande número de alunos atendidos - ganho de escala; a disponibilização de materiais em formato digital - facilitando a organização e a busca/consulta; o desenvolvimento de materiais de ensino mais ricos e variados, tais como os de aprendizagem multimídia; e a possibilidade de apoio mais amplo à educação, por não se limitar a poucas horas diárias, nem a locais fixos, como no caso do ensino presencial.

Assim, o ensino na modalidade de $\mathrm{EaD}$ exige uma equipe multidisciplinar, com diferentes competências: docentes especializados nas áreas do curso, coordenadores, técnicos especializados, designer instrucionais, designers gráficos, monitores, revisores e tutores.

Conforme dados do último Censo da Educação Superior do Ministério da Educação (INEP/MEC, 2008), há no Brasil uma permanente expansão do sistema de EaD.

\section{PROCEDIMENTOS METODOLÓGICOS}

Quanto ao tipo, o presente estudo caracteriza-se como exploratório, descritivo, documental, bibliográfico, teórico-empírico, estudo de caso. Em relação à abordagem, classifica-se como qualitativo.

Nesta pesquisa foram coletadas informações dos integrantes da equipe do Projeto Aluno Integrado, nos estados de Santa Catarina, Paraná, Mato Grosso do Sul e Rio Grande do Sul, que foi a parte do Projeto coordenada pela UFSC. 
Os dados primários foram coletados junto a coordenadores do curso (que eram da UFSC), coordenadores de tutoria (também da UFSC), coordenadores de polo (dos estados), supervisores, tutores a distância (da UFSC), tutores presenciais (em cada polo de ensino). Foram utilizadas para a coleta de dados entrevistas semiestruturadas, que foram alteradas durante o trabalho de campo, conforme as análises das entrevistas iam sendo realizadas, de acordo com o perfil dos entrevistados, como recomenda o método da GT, conforme o Quadro 1, exposto a seguir:

Quadro 1 - Variáveis em estudo e questões

\begin{tabular}{|c|l|}
\hline Questão & \multicolumn{1}{c|}{ Variável } \\
\hline 1 & Como funciona a gestão do curso de administração a distância? Quem são os agentes? \\
\hline 2 & Como a equipe de EaD é preparada? Quais são as estratégias e medidas de sucesso? \\
\hline 3 & Quais são as dificuldades enfrentadas pela equipe de EaD durante a interação da equipe? \\
\hline 4 & $\begin{array}{l}\text { Como é o relacionamento entre a equipe do Pólo e a da UFSC? Já aconteceu algum conflito, } \\
\text { exemplifique; }\end{array}$ \\
\hline 5 & Qual o tipo de desentendimento você percebe na equipe do curso? \\
\hline 6 & $\begin{array}{l}\text { Quais são os tipos de desacordos ou mal entendidos leves, ou seja, quais são os tipos de conflitos } \\
\text { existentes no grupo? }\end{array}$ \\
\hline 7 & $\begin{array}{l}\text { Quais são os principais aspectos determinantes (motivadores) que levam ao conflito? "as forças } \\
\text { em jogo/interesses”; }\end{array}$ \\
\hline 8 & Como foi realizado o gerenciamento destes problemas/conflitos? Se sim, como? \\
\hline 9 & $\begin{array}{l}\text { O que é feito para minimizar os conflitos da equipe? Como você acreditaria que desejaria ser } \\
\text { feito?; }\end{array}$ \\
\hline 10 & O que aconteceu com o desempenho do grupo?; \\
\hline
\end{tabular}
Fonte: Dados primários

Após a coleta de dados, ocorreu a seção de tratamento. Para a análise dos dados foi utilizado o software ATLASti, específico para entrevistas qualitativas, desenvolvido para auxiliar a construção de teorias, permitindo auditorias que verifiquem a validade e confiabilidade dos dados. As estratégias de análise adotadas foram: qualitativa, descritiva e interpretativa, análise do discurso; utilizando-se da metodologia da Ground Theory ou Teoria fundamentada, que auxilia na análise dos dados (STRAUSS; CORBIN, 2008).

\section{PROJETO ALUNO INTEGRADO}

O Projeto Aluno Integrado (PAI) é parte do Programa Nacional de Formação Continuada em Tecnologia Educacional (Proinfo Integrado). O programa foi criado pela Portaria $\mathrm{n}^{0}$ 522/MEC, de 9 de abril de 1997, com o nome de Programa Nacional de Informática na Educação (ProInfo). Em 2007, por meio do decreto 6300, passou a ser denominado Programa Nacional de Tecnologia Educacional (UFSC, 2010). De acordo com o site da UFSC (2010), o objetivo do Proinfo Integrado é promover o uso pedagógico das Tecnologias de Informação e Comunicação nas redes públicas de educação básica. O programa leva às escolas computadores, recursos digitais e conteúdos educacionais. Em contrapartida, estados, Distrito Federal e municípios devem garantir a estrutura adequada para receber os laboratórios e capacitar os estudantes e professores para o uso das máquinas e tecnologias.

O Projeto Aluno Integrado tem como tema central: educação e tecnologia para um mundo melhor. Dentro desse tema, busca explorar diferentes perspectivas em todas as etapas da educação básica. O curso é oferecido para alunos a partir do nono ano, com carga horária de 180 horas (cinco meses), dividido em quatro módulos. Por meio de uma plataforma desenvolvida especialmente para o aprendizado de informática à distância (Eproinfo), os jovens aprendem sobre educação à distância, história da informática, hardware (equipamentos), manutenção de computadores e sistemas operacionais. 
Para esta pesquisa foram entrevistadas 25 (vinte e cinco) pessoas, sendo: Coordenador de curso (dois); Coordenadores Proinfo - Pólos de PR, MS, SC (três); Equipe de acompanhamento e avaliação (dois); Supervisão (dois); Equipe Técnica (dois); Orientador de tutoria (seis) e Tutores de SC, PR, MS, RS (8).

\section{DESCRIÇÃO DOS RESULTADOS}

\subsection{IENTIFICAÇÕES DA ANÁLISE DE DADOS}

Para Morin (2011, p. 150), quando se analisa uma organização sob a ótica da complexidade, tem-se que "um sistema não é somente constituído de partes; ele tem qualidades, propriedades ditas emergentes, que não existem nas partes isoladas: em outras palavras, o todo é mais do que a soma das partes”. Sendo assim, o conflito como resultante de um processo de interação entre pessoas de uma equipe (tal como do projeto PAI) pode revelar, dentro do pensamento sistêmico, uma forte tendência de auto-organização do sistema. Com base nessa visão de mundo, os agentes não são analisados separadamente e sim dentro dos processos de interação entre os agentes que constituem o todo.

Realizou-se uma análise com base na lente adotada por Stacey (2006) e Axelrod e Cohen (2000), onde estes autores elencam uma série de características que compõem um Sistema Adaptativo Complexo. A análise a seguir relaciona o que os autores apresentam e de que modo isso se configura nos fatos que aconteceram durante o curso analisado, contendo esses fatos algumas características da complexidade.

Assim, apresenta-se um quadro elaborado com base nas entrevistas, relacionando os conceitos de Sistemas Adaptativos Complexos mencionados por Axelrod e Cohen (2000) e Stacey (1996) e as identificações da pesquisa. Os achados foram analisados e agrupados conforme os conceitos apresentados pelos autores.

Quadro 2 - Analise das entrevistas com base na teoria dos Sistemas Adaptativos Complexos

\begin{tabular}{|c|c|c|c|}
\hline \multicolumn{2}{|c|}{$\begin{array}{c}\text { Itens que compõem a abordagem } \\
\text { complexa }\end{array}$} & Definição & Identificações da análise de dados \\
\hline \multirow{3}{*}{ Sistema } & Agente & $\begin{array}{l}\text { Pode ser uma pessoa, uma família ou } \\
\text { uma equipe e tem a habilidade de } \\
\text { interagir com o seu meio, incluindo } \\
\text { ou não outros agentes. }\end{array}$ & $\begin{array}{l}\text { MEC, Tutores locais, Tutores UFSC, } \\
\text { Undime, Seduc. }\end{array}$ \\
\hline & Estratégia & $\begin{array}{l}\text { Um padrão de ação condicional que } \\
\text { indica o que fazer em quais } \\
\text { circunstâncias }\end{array}$ & 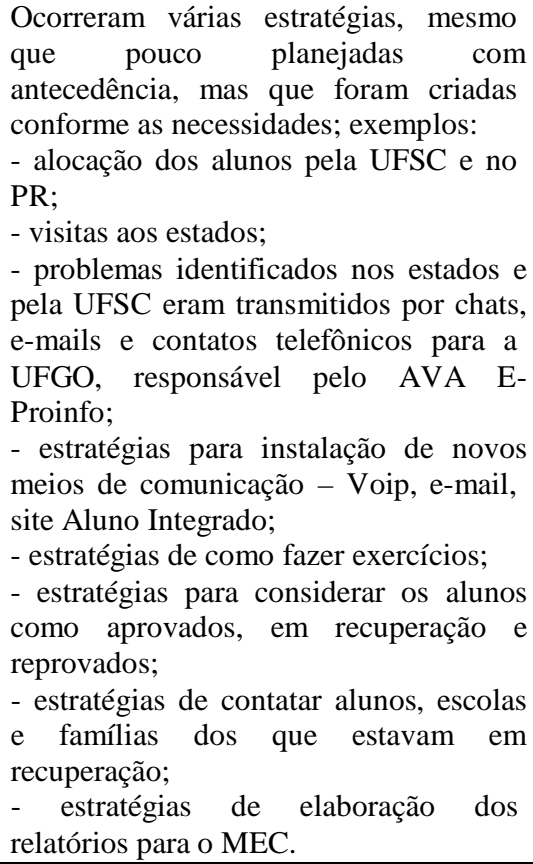 \\
\hline & Artefato & $\begin{array}{l}\text { Um recurso material que tem } \\
\text { localização definida e pode reagir às }\end{array}$ & $\begin{array}{l}\text { Computadores das escolas, da UFSC. } \\
\text { Telefones }\end{array}$ \\
\hline
\end{tabular}




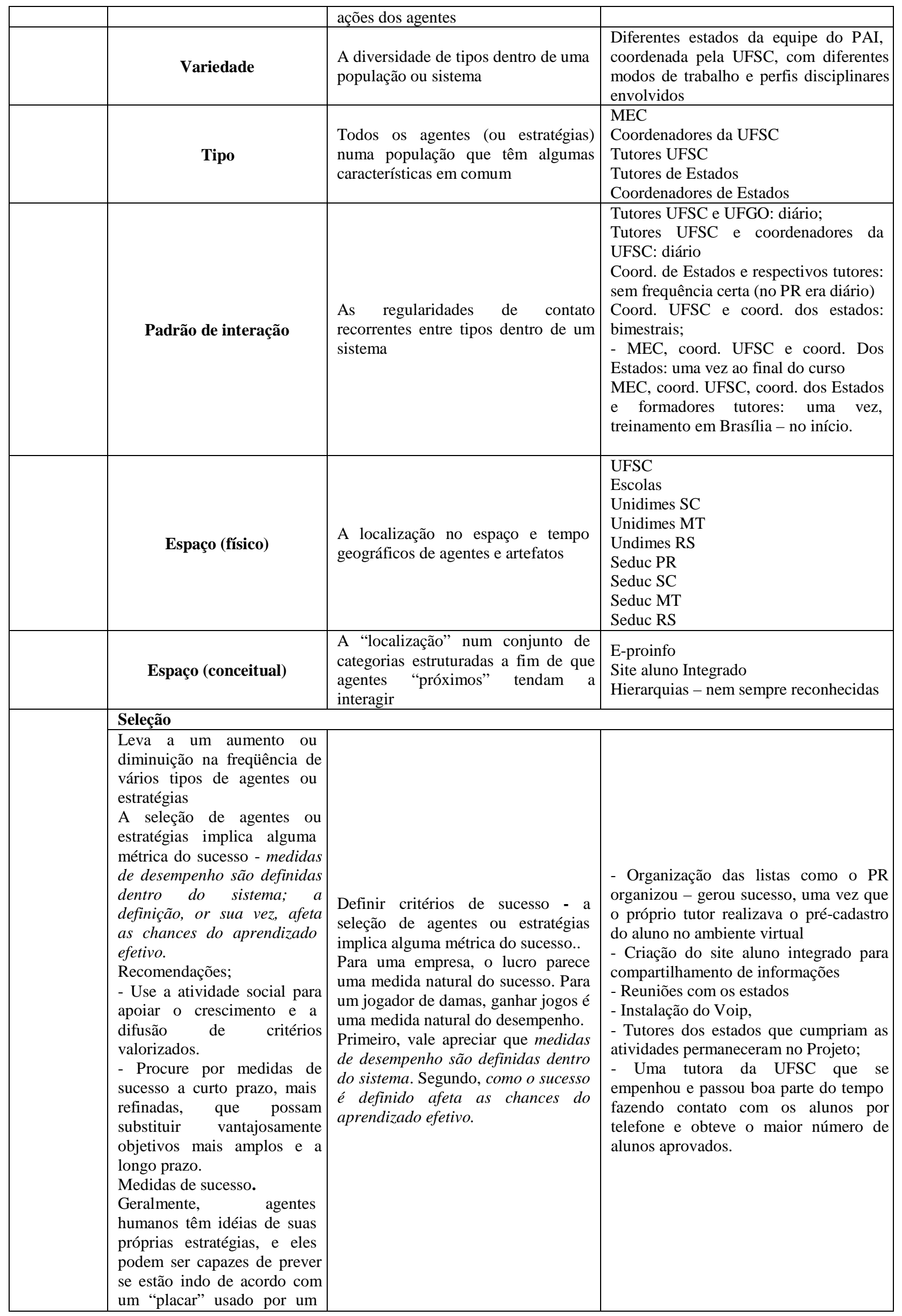




\begin{tabular}{|c|c|c|}
\hline $\begin{array}{l}\text { agente ou designer para } \\
\text { atribuir crédito na seleção de } \\
\text { estratégias ou agentes } \\
\text { relativamente bem-sucedidos } \\
\text { (ou malsucedidos). }\end{array}$ & & \\
\hline \multicolumn{3}{|l|}{ Medidas de seleção: } \\
\hline $\begin{array}{l}\text { - definir se a seleção é ao } \\
\text { nível de agentes ou de } \\
\text { estratégias }\end{array}$ & & $\begin{array}{l}\text { - Boa parte da seleção ocorreu ao nível } \\
\text { de estratégias }\end{array}$ \\
\hline $\begin{array}{l}\text { - atribuir crédito para } \\
\text { sucesso e fracasso }\end{array}$ & $\begin{array}{l}\text { Como um agente usa um critério de } \\
\text { desempenho para aumentar a } \\
\text { freqüência de estratégias bem- } \\
\text { sucedidas ou diminuir a freqüência } \\
\text { das mal-sucedidas, um passo que } \\
\text { chamamos atribuição de crédito, e } \\
\text { como os agentes ou estratégias que } \\
\text { recebem crédito são copiados, } \\
\text { recombinados ou destruídos. }\end{array}$ & $\begin{array}{l}\text { - Eram copiados conforme tinham } \\
\text { sucesso na ação, sem planejamento } \\
\text { prévio }\end{array}$ \\
\hline $\begin{array}{l}\text { - criar novos agentes ou } \\
\text { estratégias }\end{array}$ & $\begin{array}{l}\text { Da mesma forma que a diferença } \\
\text { entre a cópia de estratégias ou } \\
\text { agentes é importante, também o são } \\
\text { as diferenças detalhadas entre os } \\
\text { vários processos de cópia. }\end{array}$ & $\begin{array}{l}\text { - Inicialmente a maior liderança era } \\
\text { local - os tutores seguiam os } \\
\text { coordenadores locais determinavam }\end{array}$ \\
\hline 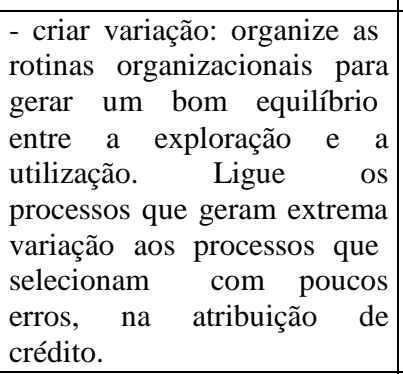 & $\begin{array}{l}\text { Para tratar de um Sistema Adaptativo } \\
\text { Complexo partiu-se da idéia de que } \\
\text { os agentes não são todos iguais. A } \\
\text { variedade é exigência para } \\
\text { adaptação. É tentador pensarmos que } \\
\text { num sistema os agentes são } \\
\text { praticamente iguais. }\end{array}$ & $\begin{array}{l}\text { - As inúmeras variações de erros } \\
\text { identificados pela equipe de tutores e as } \\
\text { muitas adaptações que foram atendidas } \\
\text { pela UFGO - } 46 \text { tipos diferentes de } \\
\text { erros no E-proinfo. } \\
\text { - Adaptação dos calendários - pois as } \\
\text { férias escolares dos estados eram em } \\
\text { momentos diferentes; } \\
\text { - As adaptações locais dos exercícios.. }\end{array}$ \\
\hline 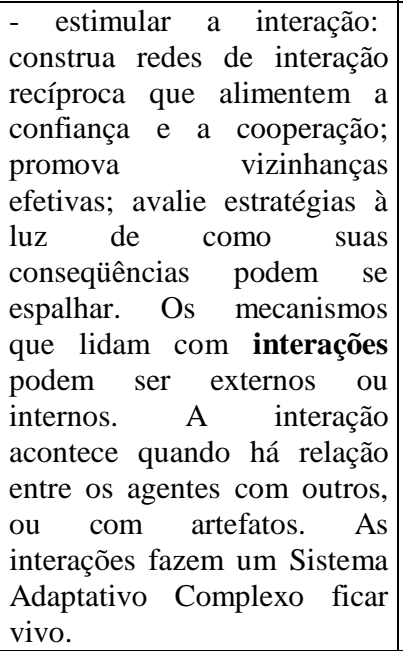 & $\begin{array}{l}\text { A questão espaço e tempo é colocada } \\
\text { como propriedade fundamental dos } \\
\text { agentes. Nos espaço físicos eles } \\
\text { estão em algum momento, em algum } \\
\text { lugar e são encontrados por um } \\
\text { endereço ou através de uma } \\
\text { informação. Dependendo do artefato } \\
\text { adotado podemos utilizar vários tipos } \\
\text { de estratégias para localizar um } \\
\text { agente. } \\
\text { cartesianas Desde } \\
\text { localização por satélite. }\end{array}$ & $\begin{array}{l}\text { Tutores UFSC e UFGO: diário; } \\
\text { Tutores UFSC e coordenadores UFSC: } \\
\text { diário; } \\
\text { - Coord. dos Estados e tutores dos } \\
\text { Estados: sem freqüência certa (no PR, } \\
\text { era diário, pois também trabalhavam } \\
\text { com Núcleo de EaD do Estado) } \\
\text { Coord UFSC e coord. dos Estados: } \\
\text { encontros bimestrais; } \\
\text { - MEC, coord. UFSC e coord. dos } \\
\text { Estados: } 1 \text { encontro ao final do curso } \\
\text { - MEC, coord. UFSC e coord. Estados e } \\
\text { formadores tutores: } 1 \text { encontro no } \\
\text { treinamento em Brasília - no início. }\end{array}$ \\
\hline
\end{tabular}

Fonte: Elaborado pela autora Aline Pereira Soares, com base em Axelrod e Cohen (2000) e Stacey (1996)

Percebeu-se durante a análise que a abordagem complexa esteve presente no caso analisado, mas não foi considerada de forma consciente e orientadora pela equipe do PAI, porque ela vai além das perspectivas comuns (normais) interpretativista e funcionalista do modelo de Burrel e Morgan (1979). Na abordagem complexa, o conhecimento é construído como produto de sistemas que se comportam de modo imprevisíveis e criativos, ou seja, longe do equilíbrio (que são mais exceção do que regra). Outrossim, nessa perspectiva os sistemas são compostos por uma multiplicidade de agentes que, para atingirem sua metas, interagem entre si, aprendem comportamentos diferentes dos iniciais e evoluem - como aconteceu no curso analisado. 
A teoria dos Sistemas Adaptativos Complexos é a que mais poderia se aproximar da realidade observada (ALLEN, 2001), pois, diferente das outras teorias, aqui o agente/sujeito analisa, interpreta, compreende e questiona, uma vez que o resultado mais importante em tal sistema está na capacidade de aprender durante seu funcionamento; todavia, no caso em foco, os agentes não registravam as estratégias (eram criadas conforme a demanda) e nem as métricas de sucesso.

Com os relatos acima, percebe-se, segundo os entrevistados, as falhas de planejamento iniciais do curso e no treinamento, ainda durante o primeiro encontro realizado em Brasília. Bem como a falta de aproveitamento de toda potencialidade que a devida compreensão e aplicação da abordagem complexa poderia proporcionar.

\section{CONCLUSÕES}

A partir dos dados do caso apresentado, pode-se perceber que muitos conflitos aconteceram, em especial, no contato inicial das equipes, quando o curso iniciou. A partir dos problemas que foram surgindo no decorrer do curso, os agentes participantes da equipe analisada aprenderam mais sobre o próprio sistema a partir de interação, variação e seleção das estratégias que tiveram maiores chances de dar certo.

Contudo, apesar de o sistema analisado poder ser associado a um Sistema Adaptativo Complexo, os agentes deveriam, conforme sugere a teoria, terem registrado as estratégias e suas medidas de sucesso por meio de relatórios que poderiam ser compartilhados com os integrantes da equipe - em especial em reuniões, caso essas acontecessem com maior frequência.

Do mesmo modo, Axelrod e Cohen (2000) afirmam que dominar a complexidade significa conviver com ela e, em situações de conflito, que a organização consiga aprender com a situação, em vez de tentar ignorá-la ou eliminá-la. Assim, ao serem questionados sobre as possíveis soluções para o conflito / para que os desentendimentos não voltassem a acontecer, e o aprendizado fosse mais efetivo, os entrevistados solicitaram: mais encontros presenciais e maior quantidade de treinamento; troca do ambiente virtual (para algo mais fácil, como por exemplo, o Moodle); acesso a vídeos explicativos; acesso a um canal de comunicação (Voip) aproximador das equipes e de rápido contato; capacitação dos professores e tutores antes do início do curso; maior autonomia e definição de papéis; melhor infraestrutura de escolas.

Desse modo, espera-se que a pesquisa contribua para que as instituições que trabalham com Educação a Distância tenham melhor planejamento de suas ações, especificamente das TICs - incluindo como fonte de ajustes e aperfeiçoamento as opiniões das equipes que atuam cotidianamente com os alunos.

\section{REFERÊNCIAS}

ALLEN, Peter M. What is complexity science? Knowledge of the limits to knowledge. Emergence, v. 3, n. 1, p. 24-42, 2001

AXELROD, R. M. and COHEN, M.D. Harnessing Complexity: Organizational Implications of a Scientific Frontier. New York: The Free Press, 2000.

BAUER, Ruben. Gestão da mudança: caos e complexidade nas organizações. São Paulo: Atlas, 2008.

CASTRO, Gustavo; et al. (Org.). Ensaios da Complexidade. Porto Alegre: Sulina, 1994.

DRENTH, Pieter J. D.Principles and Methods. En PJ.D. Drenth, H. Thierry y C.J. de Wolff (Eds.), Handbook of Work and Organizational Psychology, Intrduction to Work and Organizational Psychology, pp. 11-41. East Sussex Psychology Press, 1998.

ETKIN, Jorge; SCHVARSTEIN, Leonardo. Identidad de las organizaciones: invariância y cambio. Buenos Aires: Paidós, 2000. 
HOLLAND, J. Hidden Order. How adaptation builds complexity. Cambridge: Perseus Books, 1995.

HOLLAND, John H. Emergence: from chaos to order. Cambridge: Perseus Books, 1998.

INEP/MEC. Educacenso. Anuário Brasileiro Estatístico de Educação Aberta e a Distância. 4. ed. São Paulo, 2008. Disponível em: <http://www.abraead.com.br/default.asp>. Acesso em: 10 dez. 2011.

KELLEY, E. Keys to effective virtual global teams. The Academy of Management Executive, v. 15, n. 2, p. 132-133, may 2001.

KLERING, L. R. Plataforma de apoio ao ensino NAVi: ambiente interativo de aprendizagem. 2006. Disponível em: <http://eavirtual.ea.ufrgs.br>. Acesso em: 10 dez. 2011.

MALLORY, G. A. Believe it or not: Conflict can be Healthy Once you Understand it and Learn to Manage it. Nursing v. 81, New York, 1997.

MOORE, M. G; KEARSLEY, G. Distance education: a systems view. Wadsworth Publishing Company, 1996.

. Educação à distância: uma visão integrada. São Paulo: Thomson, 2007.

MORIN, E..Epistemologia da complexidade; In SCHNITMAN, D. F. (org.) Novos paradigmas, e cultura e subjetividade Porto Alegre: Artes Médicas, 1996.

. Notas para um "Emílio" contemporâneo. In: VEGA, A.P.; ALMEIDA, C.R.S.; PETRAGLIA, I. (Org). Edgar Morin: ética, cultura e educação. São Paulo: Cortez, 2001.

O método 1: a natureza da natureza. Porto Alegre: Sulina, 2005.

NONAKA, I.; TAKEUCHI, H. The Knowledge Creating Company. Oxford University Press, 1995.

PRIM, Carlos. Processo empreendedor e coevolução em organizações intensivas em conhecimento. 2008. Tese (Doutorado em Engenharia e Gestão do Conhecimento) Programa de Pós-graduação em Engenharia e Gestão do Conhecimento, Universidade Federal de Santa Catarina, Florianópolis. Disponível em <http://btd.egc.ufsc.br/?p=141> Acesso em out. 2009.

ROSINI, A. M. As novas tecnologias da informação e a educação a distância. São Paulo: Cengage Learning, 2007.

SEDUC/GO. Secretaria de Educação do Estado de Goiás. Abertas incrições para curso de qualificação em tecnologia digital na UFG. Disponível em: <http://www.educacao.go.gov.br/imprensa/?Noticia=3332>. Acessado em: 08 maio 2012.

SIMONSON, M.. Concepciones sobre la educación abierta y a distancia.. In: BARBERÀ, E. (Coord.). Educación abierta y a distancia. Barcelona: UOC, 2006.

STACEY, Ralph D Complexity and creativity in organizations. San Francisco. BerretKoehler Publishers, 1996.

STACEY, Ralph D. Complex responsive processes in organizations: Learning and Knowledge Creation. London: Routledge, 2001.

STACEY, Ralph D.; GRIFFIN, Douglas; SHAW, Patricia. Complexity and management: fad or radical challenge to systems thinking? New York: Routledge, 2000.

STRAUSS, A.; CORBIN, J. Pesquisa qualitativa: técnicas e procedimentos para o desenvolvimento de uma teoria fundamentada. 2. ed. Porto Alegre: Artmed, 2008.

UFSC. Universidade Federal de Santa Catarina. Projeto Aluno Integrado. Disponivel em: <http://www.alunointegrado.ufsc.br/node/2>. Acesso em: 19 out. 2010. 